\title{
HIGHWAY INFRASTRUCTURE HEALTH MONITORING USING MICRO- ELECTROMECHANICAL SENSORS AND SYSTEMS (MEMS)
}

\author{
Halil CEYLAN ${ }^{\mathrm{a}}$, Kasthurirangan GOPALAKRISHNAN ${ }^{\mathrm{b}}$, Sunghwan $\mathrm{KIM}^{\mathrm{c}}$, Peter C. TAYLOR ${ }^{\mathrm{d}}$, \\ Maxim PROKUDIN ${ }^{\mathrm{e}}$, Ashley F. BUSS \\ ${ }^{a} 406$ Town Engineering Building, Iowa State University, Ames, IA 50011-3232, USA \\ ${ }^{b} 354$ Town Engineering Building, Iowa State University, Ames, IA 50011-3232, USA \\ ${ }^{c} 24$ Town Engineering Building, Iowa State University, Ames, IA 50011-3232, USA \\ ${ }^{d}$ Institute for Transportation, Iowa State University, Ames, IA 50010-8664, USA \\ ${ }^{e}$ Town Engineering Building, Iowa State University, Ames, IA 5001-3232, USA
}

Received 01 Dec 2011; accepted 18 Apr 2012

\begin{abstract}
The development of novel "smart" structures by embedding sensing capabilities directly into the construction material during the manufacturing and deployment process has attracted significant attention in autonomous structural health monitoring (SHM). Micro-electromechanical systems (MEMS) provide vast improvements over existing sensing methods in the context of SHM of highway infrastructure systems, including improved system reliability, improved longevity and enhanced system performance, improved safety against natural hazards and vibrations, and a reduction in life cycle cost in both operating and maintaining the infrastructure. Advancements in MEMS technology and wireless sensor networks provide opportunities for long-term, continuous, real-time structural health monitoring of pavements and bridges at low cost within the context of sustainable infrastructure systems. Based on a comprehensive review of literature and vendor survey, the latest information available on off-the-shelf MEMS devices, as well as research prototypes, for bridge, pavement, and traffic applications are synthesized in this paper. In addition, the paper discusses the results of a laboratory study as well as a small-scale field study on the use of a wireless concrete monitoring system based on radio-frequency identification (RFID) technology and off-the-shelf MEMS-based temperature and humidity sensors.
\end{abstract}

Keywords: MEMS, concrete, health monitoring, sensor, laboratory testing, PCC maturity, RFID, temperature, humidity.

Reference to this paper should be made as follows: Ceylan, H.; Gopalakrishnan, K.; Kim, S.; Taylor, P. C.; Prokudin, M.; Buss, A. F. 2013. Highway infrastructure health monitoring using micro-electromechanical sensors and systems (MEMS), Journal of Civil Engineering and Management 19(Supplement 1): S188-S201.

http://dx.doi.org/10.3846/13923730.2013.801894

\section{Introduction}

Micro-electromechanical sensors and systems (MEMS) claim to be the smallest functional machines that are currently engineered by humans (Korvink, Paul 2006). These micro machines began their development as early as the 1970 s, but, since 1995, there has been significant progress given a variety of new materials and bulk micromachining, which has led to new applications for MEMS (Gaura, Newman 2006).

MEMS have been developed in many areas including the medical and automotive industries. There are a number of research projects exploring ways to apply the MEMS technology to help enhance structural health monitoring (SHM) practices in civil engineering.

By incorporating MEMS sensor technology into SHM of highway infrastructure, there are potential benefits that include improved system reliability, improved longevity and enhanced system performance, improved safety against natural hazards and vibrations, and a reduc- tion in life cycle cost in both operating and maintaining the infrastructure (Attoh-Okine 2003). The functions of sensing and actuating with computation and communication are merged in MEMS technology to locally control physical parameters at the micro scale. A number of duplicate devices joined together can cause effects at much greater scales. Figure 1(a) shows the main components of MEMS (Attoh-Okine 2003).

MEMS devices can be classified into three broad categories (Maluf 2000): sensors, actuators, and passive structures. Transducers that convert mechanical, thermal, or other forms of energy into electrical energy are considered sensors; whereas, actuators do the exact opposite. Devices in which no transducing occurs are passive structures. Some intrinsic properties, such as piezoresistivity, piezoelectricity, or thermoelectricity of the component, determine the actuation or sensing ability of MEMS (Attoh-Okine 2003).

Nano-electromechanical systems (NEMS) devices are similar to MEMS with typical device dimensions in 
the nanometer range. The distinction between MEMS and nanotechnology is often not so clear, although they are cited as separate technologies. In reality, they have overwhelming mutual dependencies and, this trend is expected to increase as these and other related technologies evolve with time.

There are four major process steps in manufacturing MEMS: design, fabrication, packaging and testing. These steps determine the final product's performance and price (Attoh-Okine 2003). The process flow sequence for fabrication of MEMS devices is depicted in Figure 1b.

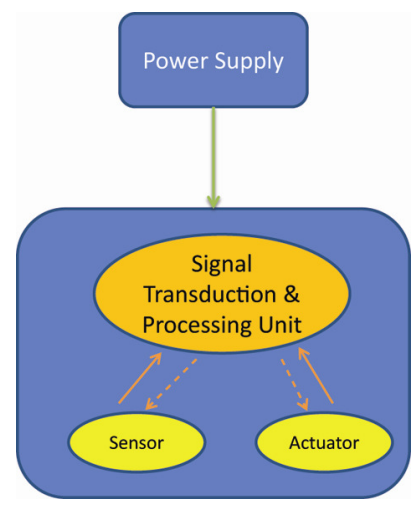

a)

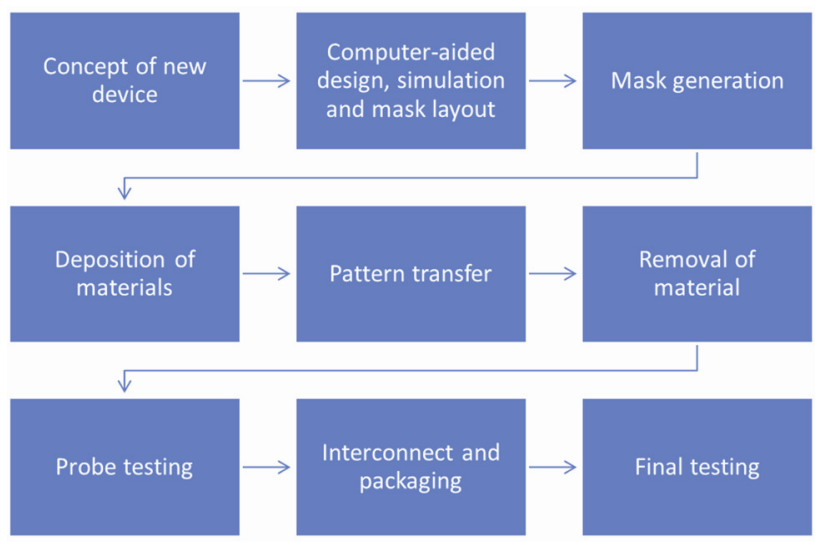

b)

Fig. 1. MEMS components and fabrication: a) Main components of MEMS (after Attoh-Okine 2003); b) Process flow sequence for MEMS device fabrication (after Tanner 2001; Mensah 2003)

MEMS technology could potentially help pavement monitoring by obtaining in situ condition data. This data would tell engineers when and where pavement deterioration is occurring before the distress is noticeable to the traveling public.

The following are some areas of highway infrastructure condition monitoring where the application of MEMS technology is actively being researched or is identified for future research (Fig. 2):

- Micrometer strain gauge for geotechnical testing (triaxial testing) and asphalt material testing (resilient modulus test);

- Microsensors to measure pavement roughness and temperature;
- Crack monitoring of bridges;

- Temperature monitoring of bridges during the winter to alert drivers to the condition of bridges;

- Electromechanical sensors to detect and monitor corrosion in steel structures, especially welding joint and load transfer devices in rigid pavements;

- Microfluidic applications to identify the alkalisilica reaction in concrete structures;

- Microcrack monitoring in concrete;

- Monitoring geotextile performance within pavement systems;

- Reliability of welding units in structural steel;

- "Smart Pebbles" - long-life wireless sensors that continually monitor the health of concrete bridge structures from deep inside the bridge deck;

- "Smart Aggregates" - Embedded wireless sensors to measure $\mathrm{pH}$, moisture, temperature, and concentrations of chloride, sodium, and potassium ions within the concrete:

- Temperature measurements during placement and curing for monitoring uniformity of the concrete mix, rate of the hydration reaction, and potential for thermal cracking using a well-distributed network of temperature sensors;

- Electronic $\mathrm{pH}$ sensors for detecting and identifying several deteriorations in concrete structures, including the presence of chloride ions, carbonation, and leaching of calcium hydroxide;

- Assessment of overall durability and strength of concrete using moisture sensor measurements;

- Investigation of the concrete mixing process leading to optimization of mix designs and mixers;

- Measurement of subsequent compaction and shrinkage after placement of concrete.

- Measurement of large-scale strains in soil foundations.

The following are some of the recently completed comprehensive studies/reviews on the state-of-the-art in MEMS-based highway/transportation infrastructure research which were also extensively consulted in conducting the literature review for this paper:

- Applicability of Microelectronic and Mechanical Systems (MEMS) for Transportation Infrastructure Management (Wang, Li 2008);

- Nanotechnology Synthesis Study: Research Report (Liu et al. 2007);

- Use of micro-electro-mechanical systems and wireless sensor networks on road infrastructures (Iaquinta 2008).

\section{MEMS in highway infrastructure monitoring: state-of-the-art review}

MEMS integrated in a wireless network can help to make a low-cost, manageable way to monitor transportation infrastructure systems. The potential applications of MEMS- 


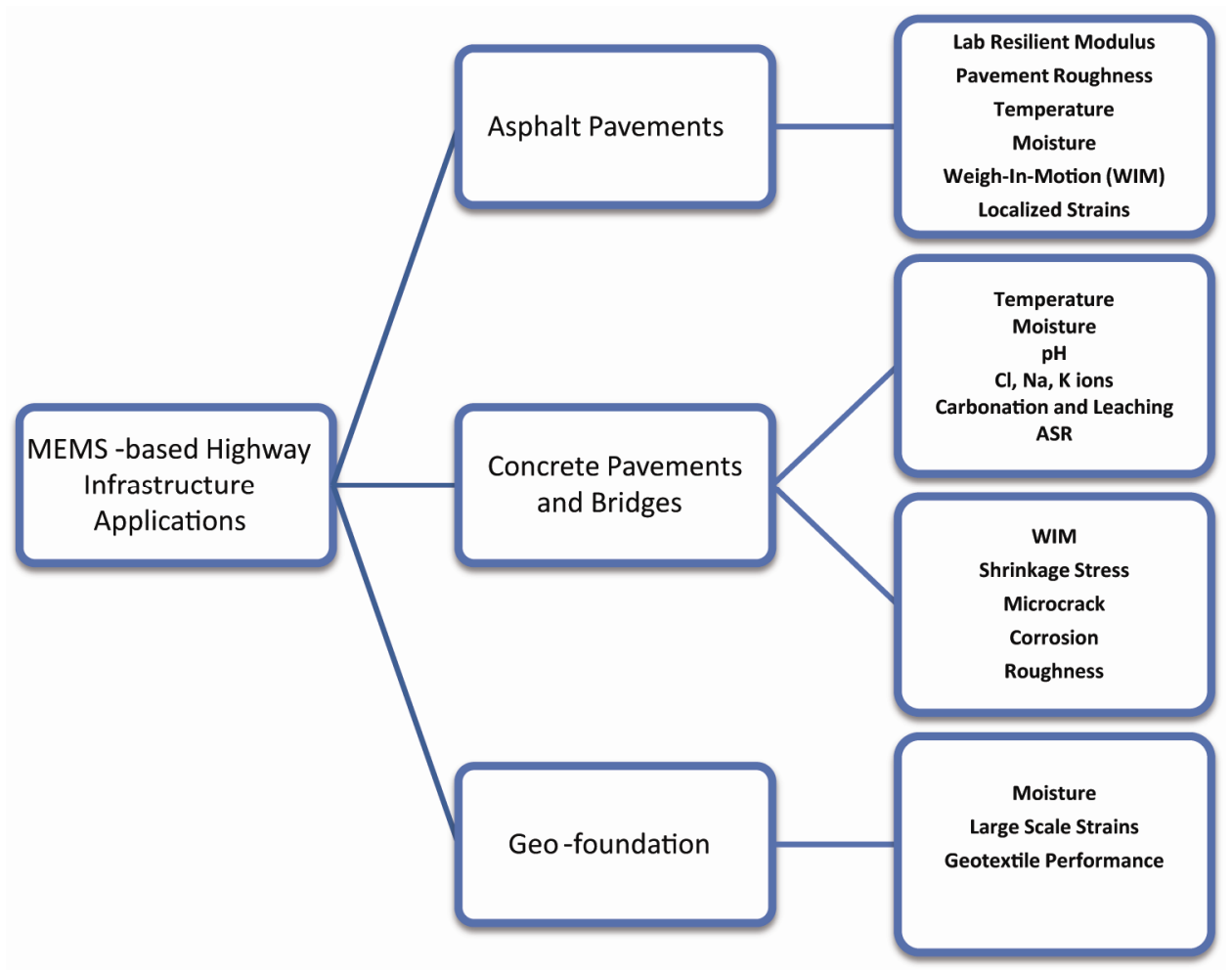

Fig. 2. Summary of existing or potential MEMS-based highway infrastructure applications reported in the literature

and nanotechnology-based sensor devices and networks for transportation infrastructure applications are summarized in Table 1, which highlights the latest information on the availability of the associated MEMS sensors/systems (Liu et al. 2007).

Some of the highlighted research studies discussed in this section include the development of the Wireless Embedded Sensor Platform (WESP) at the John Hopkins University Applied Physics Laboratory (APL) (Darrin et al. 2004; Srinivasan et al. 2005), Smart Pebbles at the California Department of Transportation (Caltrans) and SRI International (Watters et al. 2003), and more recently the Smart Pavement Monitoring System being developed at Michigan State University (Lajnef et al. 2011).

\subsection{MEMS concrete monitoring system}

Many of the monitored structures in the civil infrastructure are made out of concrete. This is also applicable to pavements. Concrete's properties, like strength and durability, depend heavily on temperature and moisture. A rapid loss of moisture can lead to a lower strength development, which can lead to early damage to a structure (Saafi, Romine 2005). Monitoring temperature and moisture distribution in concrete structures will help engineers determine concrete strength and the severity of shrinkage cracking (Saafi, Romine 2005). MEMS embedded in concrete could help engineers to more efficiently monitor the curing process of concrete. These properties are important because understanding the rate of drying is useful in determining the properties or physical condition of the concrete (Kosmatka et al. 2002). Concrete needs moisture to cure and, if moisture is not present, concrete ceases to gain strength.
Norris et al. (2008) experimentally and analytically investigated the use of nanotechnology/MEMS to monitor and temperature and internal relative humidity of concrete using microcantilever beams and moisturesensitive thin polymer. According to a recent feasibility study published by Saafi et al. (2010), embedded wireless MEMS and nanotechnology-based sensors have the potential to form self-sensing concrete structures that could detect the early formation of tiny cracks and measure the rate of temperature, moisture, chloride, acidity, and carbon dioxide levels, etc. each of which might reflect a decrease in structural integrity.

Advanced Design Consulting, Inc. has recently developed the prototypes of the MEMS Concrete Monitoring System by integrating the temperature, humidity, and moisture sensors to the RFID system using a modular systems approach. This concept is similar to a personal computer (PC) motherboard integrated with sound card, video card, etc. with different functionalities. Together with the sensors, a number of Radio Frequency (RF) antennas are also integrated to transmit the wireless signal when queried using a RFID communications system. The sensors are approximately the diameter of a quarter and they combine RFID with MEMS in a package that can withstand being mixed with concrete (Advanced Design Consulting 2008).

\subsection{John Hopkins University Applied Physics Laboratory WESP}

The John Hopkins University Applied Physics Laboratory (APL), with help from the Maryland State Highway Administration, has developed a passive wireless sensor system (Wireless Embedded Sensor Platform or WESP). 
Table 1. Existing and potential nanotechnology- and MEMS-based sensor systems for transportation applications

\begin{tabular}{|c|c|c|}
\hline $\begin{array}{l}\text { MEMS/Nano Sensors } \\
\text { and Systems }\end{array}$ & Potential Application & Availability \\
\hline Temperature sensor & $\begin{array}{l}\text { Temperature monitoring } \\
\text { and concrete strength } \\
\text { estimation using PCC } \\
\text { maturity concept }\end{array}$ & $\begin{array}{l}\text { Commercial products available: } \\
\text { - Q350 series by Identic Solutions (wireless) } \\
\text { - Embed Sensor by MicroStrain, Inc. (wireless) } \\
\text { - IntelliRock by Engius (wired) } \\
\text { - GT-301 by GENTAG, Inc. (wireless) } \\
\text { - Temperaure iButtons by Maxim (wired) } \\
\text { - Digital temperature sensor by Sensiron (wired) } \\
\text { Research prototypes may be available, but no commercial product: } \\
\text { - Early age concrete property monitoring (Saafi, Romine 2005) } \\
\text { - Monitoring pavement condition using "Smart Dust" } \\
\text { (Pei et al. 2007) } \\
\text { - Advanced Design Consulting (ADC) }\end{array}$ \\
\hline Moisture sensor & $\begin{array}{l}\text { Moisture/Humidity } \\
\text { monitoring }\end{array}$ & $\begin{array}{l}\text { Commercial products available: } \\
\text { - Humidity iButtons by Maxim (wired) } \\
\text { - Digital humidity sensor by Sensirion (wired) } \\
\text { Research prototypes may be available, but no commercial product: } \\
\text { - Early age concrete property monitoring (Saafi, Romine 2005) } \\
\text { - Monitoring pavement condition using "Smart Dust" } \\
\text { (Pei et al. 2007) } \\
\text { - Passive, wireless inductor-capacitor (LC) resonant circuit } \\
\text { (Ong et al. } 2008 \text { ) } \\
\text { - Advanced Design Consulting (ADC) } \\
\text { - Identec Solutions }\end{array}$ \\
\hline MEMS accelerometer & $\begin{array}{l}\text { Bridge and highway } \\
\text { safety monitoring }\end{array}$ & $\begin{array}{l}\text { Commercial products available: } \\
\text { - Triple-axis accelerometer board by freescale (wireless) } \\
\text { - 3-Axis Magnetic Sensor by Honeywell (wireless) } \\
\text { Research prototypes may be available, but no commercial product: } \\
\text { - Stop sign monitoring sensor network (Liu et al. 2007) } \\
\text { - Characterization of rolling resistance of a truck wheel (Iaquinta 2008) } \\
\text { - Safe inter-vehicle distance network (Iaquinta 2008) }\end{array}$ \\
\hline $\begin{array}{l}\text { Load/strain/stress } \\
\text { sensor }\end{array}$ & $\begin{array}{l}\text { Monitor load condition } \\
\text { and/or measure strain } \\
\text { and stress information } \\
\text { of pavements and briges }\end{array}$ & $\begin{array}{l}\text { Commercial products available: } \\
\text { - Sensor networks by Crossbow Technology, Inc. (Wireless) } \\
\text { - Sensor networks by Sensicast (Wireless) } \\
\text { Research prototypes may be available, but no commercial product: } \\
\text { - MEMS strain sensor (Obadat et al. } 2003 \text { ) } \\
\text { - Early age concrete property monitoring (Saafi, Romine 2005) } \\
\text { - Microwave Weigh-In-Motion (WIM) sensor (Liu et al. 2007) } \\
\text { - Smart pavement monitoring system (Lajnef et al. 2011) }\end{array}$ \\
\hline $\begin{array}{l}\text { Chloride detection } \\
\text { sensor }\end{array}$ & $\begin{array}{l}\text { Monitor the intrusion of } \\
\text { rust-inducing salt }\end{array}$ & $\begin{array}{l}\text { Research prototypes may be available, but no commercial product: } \\
\quad-\text { Smart Pebbles (Watters et al. 2003) }\end{array}$ \\
\hline $\begin{array}{l}\text { Corrosion/crack } \\
\text { detection sensor }\end{array}$ & $\begin{array}{l}\text { Monitor corrosion rate, } \\
\text { conductivity, coating } \\
\text { heal monitor (CHM), } \\
\text { water corrosivity, or } \\
\text { hidden crack }\end{array}$ & $\begin{array}{l}\text { Research prototypes may be available, but no commercial product: } \\
\text { - John Hopkins "Smart Aggregate" (Darrin et al. 2004) } \\
\text { - Comparative Vacuum Monitoring (CVM) Device (Sandia National } \\
\text { Labs 2007) } \\
\text { - Cement CNT sensors (Saafi, Kaabi 2009) }\end{array}$ \\
\hline $\begin{array}{l}\text { MEMS ultrasonic } \\
\text { device }\end{array}$ & $\begin{array}{l}\text { Monitor conditions at } \\
\text { critical locations in steel } \\
\text { bridge girders or truss } \\
\text { members }\end{array}$ & $\begin{array}{l}\text { Research prototypes may be available, but no commercial product: } \\
\text { - Carnegie Mellon MEMS ultrasonic device (Ozevin et al. 2006) }\end{array}$ \\
\hline $\begin{array}{l}\text { Roadside air quality } \\
\text { monitoring system }\end{array}$ & $\begin{array}{l}\text { Monitor road side air } \\
\text { quality }\end{array}$ & $\begin{array}{l}\text { Research prototypes may be available, but no commercial product: } \\
\text { - Roadside air quality monitoring system using integrated SensorChip } \\
\mathrm{CO}_{2} \text { sensor of photonics, Inc. (Iaquinta 2008) }\end{array}$ \\
\hline
\end{tabular}


It is designed to be embedded into concrete and take sensor readings from within a bridge deck (Darrin et al. 2004). Because it is a passive sensor, there is no internal battery and the device is powered when the user places a coil carrying an electric current in the proximity of the instrument that is embedded in concrete (Srinivasan et al. 2005).

The reader can send the data to a data logger or PC for analysis. The miniature wireless EIS sensor has been tested, so far, in three different mediums: concrete, water, and coatings. In addition, the sensor was tested against a simple resistor-capacitor (RC) circuit. The WESP has been tested and proven for the following applications: corrosion rate sensor, conductivity sensor, coating heal monitor (CHM), and water corrosivity monitoring (WCM).

Each WESP sensor contains a wireless power receiver and data transmission coils. To sustain concrete's harsh environment, (including mechanical stresses and high $\mathrm{pH}$ ), the sensor is designed using ceramic hybrid integrated circuit technology. The WESP sensors have a projected lifetime of 50 years. The long lifetime is achievable because the wireless power transmission allows the embeddable sensors to remain maintenance free. Prototypes of the WESP system that include sensors have been created and the reliability of this system is being tested (Kuennen 2004).

\subsection{Smart Pebbles}

Smart structure technology and MEMS are inseparable themes. In the report, Health Monitoring of Bridges, Structures and Components Using Smart-Structure Technology, a detailed description is given of the attributes that must be incorporated into a health monitoring system to be considered "smart": self-diagnostic, real-time, continuous sensing, self-organizing, etc. (Phares et al. 2005).

Smart Pebbles were being developed by SRI International for the California Department of Transportation (Caltrans). The smart pebble is a wireless passive sensor that is approximately the size of a piece of gravel. The SRI team built the device by linking a new type of chloride sensor to an off-the-shelf wireless communications chip and packaging it with cement-like materials. The sensor develops a voltage that is dependent on the salt concentration. This helps indicate if reinforcing bars are corroding (Technology Review 2003). Currently, no future developments are underway for the Smart Pebble sensor.

\subsection{Moisture content monitoring wireless sensor}

The importance of monitoring moisture content in waterpermeable transportation infrastructure cannot be underestimated. It is important to accurately determine the water requirement of the PCC mixture to ensure its longterm reliability. In the case of asphalt mixtures, the presence of unwanted moisture leads to stripping and debonding of asphalt and aggregate particles.

Ong et al. (2008) developed a wireless, passive, embedded sensor for real-time monitoring of moisture content in civil engineering materials, such as sands, subgrade soils, and concrete materials. The water-content monitoring sensor was based on a passive, wireless inductor-capacitor (LC) resonant circuit which, when embedded in test samples, remotely measures the internal water content of samples by tracking the changes in the sensor's resonant frequency.

Ong et al. (2008) also identified several potential applications of the LC sensor in transportation engineering projects such as for monitoring trapped water in asphalt pavement resulting from precipitation, snowmelts, subsurface water tables, and runoff and monitor water trapped in pavement substructures (base, subbase, subgrade, and pile structures), which cause frost-heave issues, subsurface erosion, pavement depression, and loss of structural integrity.

\subsection{Pavement strain monitoring system}

Under the FHWA Contract DTFH61-08-00024, researchers at Michigan State University are developing construction material-sized autonomous self-powered usage (battery-less) sensors for deployment in pavement structures to monitor the statistics of localized strain for early damage detection and future condition evaluation in the context of pavement network management (Lajnef et al. 2011). The long-term sensing system design is based on the integration of a piezoelectric transducer with an array of ultra-lowpower floating-gate computational circuits (Huang et al. 2010; Lajnef et al. 2008). Pavement fatigue life can be predicted using the strain-history stored in a series of memory cells using Miner's rule employed in the Mechanistic-Empirical Pavement Design Guide (MEPDG).

\subsection{Roadway ice detection system}

Pei et al. $(2007,2009)$ developed a "Smart Dust" wireless sensor network for monitoring pavement temperature and moisture presence to detect icy road condition. The system was developed based on off-the-shelf sensor network products.

An ice-detection algorithm, was developed and embedded into the sensors to categorize pavement surface conditions (dry, wet, frozen, and others) based on sensor measurements. Based on the proposed algorithm to detect icy road conditions, three types of sensors were selected for interfacing with the Mica 2 motes used in this study. Mica 2 motes represent the third-generation mote module of the "Smart Dust" wireless network developed by Crossbow.

Surge-time synchronization technology was used to enable the wireless sensor network to operate in a lowpower consumption mode. A series of field tests conducted to test the survivability of fragile sensors in harsh roadway conditions led to the development of a SensorRoad Button (SRB) (Pei et al. 2009).

\section{Experimental study description}

An experimental study with laboratory as well as field components was undertaken to investigate the feasibility of off-the-shelf MEMS-based passive sensor systems for monitoring concrete. Passive sensor systems require the 
use of a reader or interrogator to transmit an electromagnetic field to activate the sensor to begin transmitting data (Durfee, Goodrum 2002). When the reader is not activating the electromagnetic field, the sensor does not transmit any data, nor is it using any power. Active sensors, on the other hand, are equipped with an internal battery that transmits information to the reader at a specified time interval. Active sensors are generally more expensive, larger in size, have a life span limited to the internal battery power supply, have a higher memory capacity, and information can be sent from the sensor to the reader and vice versa (Durfee, Goodrum 2002). The commercially available active MEMS sensor systems were not considered in this study because the sensor dimensions were large and not embeddable in concrete.

The HardTrack Concrete Monitoring System from WAKE, Inc. and a Digital Humidity Sensor (SHT) from Sensirion, Inc., were selected for this study and are briefly reviewed below. As a reference MEMS sensor, the Thermochron iButtons from Maxim Integrated Products were also used.

\subsection{Sensor systems}

The HardTrack Concrete Monitoring System from WAKE uses RFID technology to gather temperature data of in-situ concrete in a very efficient and cost effective method. The system consists of a RFID transponder called an i-Q32T tag (by IDENTEC SOLUTIONS) and a portable transceiver called a Pro (WAKE, Inc. 2010).

The i-Q32T tag has the capability to capture the ambient temperature of the concrete it is buried in and to communicate the information to the portable Pro. The $\mathrm{i}-\mathrm{Q} 32 \mathrm{~T}$ contains an internal MEMS sensor for temperature monitoring that measures and logs the temperature in definable intervals. The collected data could be imported into the portable hand-held Pro, wirelessly for maturity calculation and saving data to the PC for posterity. The use of two-way RF communication between the buried tag and a handheld PC enables the PC to read and write data to the RFID tag. The brand new i-Q350 series of RFID tags provide an even larger communication range of up to $500 \mathrm{~m}(1,640 \mathrm{ft})$.

Sensirion, Inc. has developed a pin type of relative humidity and temperature sensor (SHT 7x series), combined with the analog and digital signal processing circuitry, on a tiny silicon chip using MEMS technology. The humidity sensor element is built out of a capacitor consisting of a pair of conductors separated by a dielectric (Sensirion, Inc. 2010). The dielectric of polymer absorbs or releases water proportional to the relative environmental humidity, and thus changes the capacitance of the capacitor. This change in capacitance can be measured by an electronic circuit, which allows the relative air humidity to be determined. A micro-machined finger electrode system with different protective and polymer cover layers forms the capacitance for the sensor chip, and, in addition to providing the sensor property, simultaneously protects the sensor from interference. The following designations are used for the sensors in the rest of the paper: 'Wireless_RFID', 'SHT', and 'iButton'.

\subsection{PCC slab instrumentation and data acquisition}

A concrete slab form was fabricated in the laboratory to install the selected MEMS sensors. Non-wireless (wired) Thermochron iButtons were also installed as reference MEMS sensors for temperature measurements. The final design dimensions of the concrete slab were $50 \times 50 \times$ $20 \mathrm{~cm}(20 \times 20 \times 8 \mathrm{in}$.). A total of 19 of sensors were installed at three different locations of the slab (center, edge, and corner of slab). Figure 3 illustrates the layout of sensor installations within the formwork before the pouring of concrete.

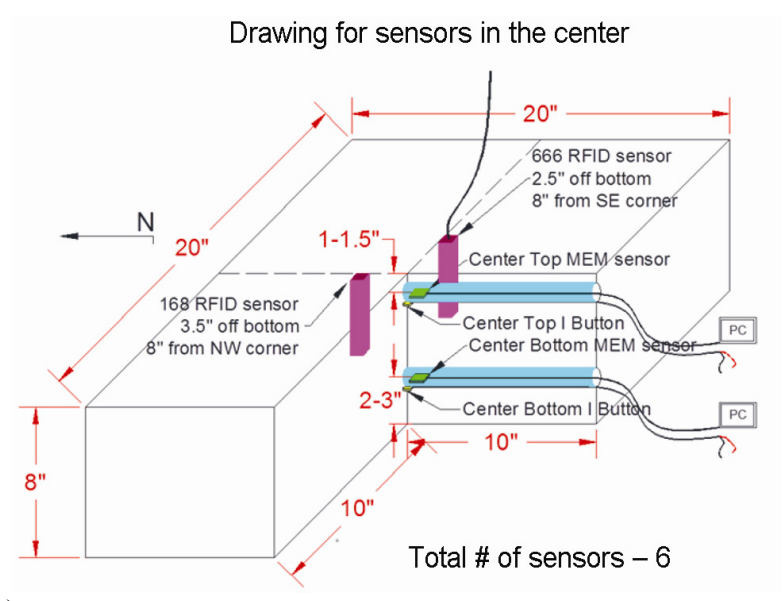

a)

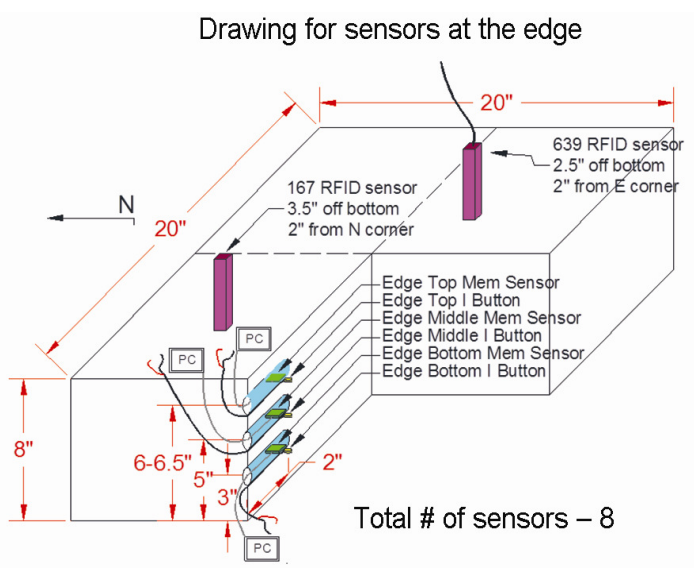

b)

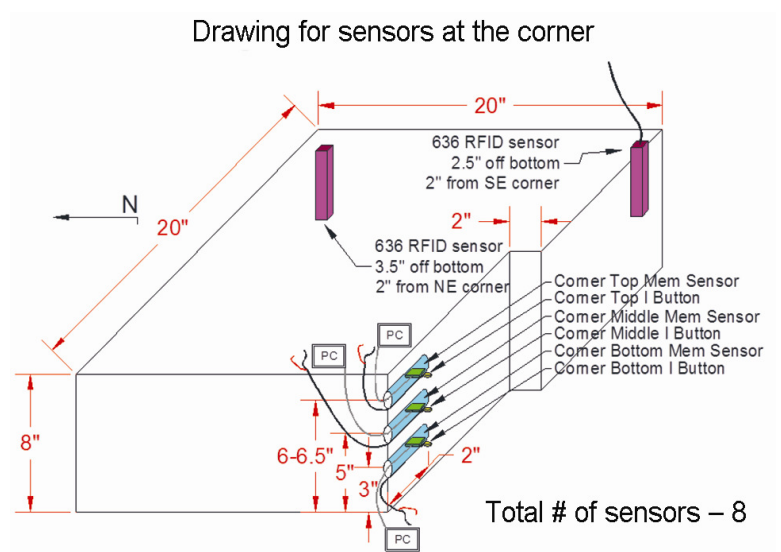

c)

Fig. 3. Layout of sensor installations: a) center; b) edge;

c) corner $(1 "=2.54 \mathrm{~cm})$ 
A concrete form was custom fabricated with holes to accommodate the sensor installation. A total of five sensors were located right at the center of the slab: two iButtons at the top and bottom of the slab, two digital humidity sensors at the top and bottom of the slab, and one wireless RFID sensor in the middle. Seven sensors were installed in the slab corner: an iButton and a digital humidity sensor at the top, middle, and bottom of the slab and one wireless RFID sensor in the middle. Likewise, seven sensors were installed along the slab edge with the same configuration. Figure 4 illustrates the concrete slab form with the sensor installations.

After the sensors were installed in the concrete form, concrete mix was prepared following a typical Iowa concrete pavement mix specification:

- Water-to-cement ratio: 0.45 ;

- Cement: $315 \mathrm{~kg} / \mathrm{m}^{3}$ (530 lbs/cubic yard);

- Fly ash: $55 \mathrm{~kg} / \mathrm{m}^{3}$ (95 lbs/cubic yard);

- Fine and coarse aggregates: $1720 \mathrm{~kg} / \mathrm{m}^{3}$ $(2,900 \mathrm{lbs} /$ cubic yard $)$. mixing:

The following are the fresh concrete properties after

- Slump: $10 \mathrm{~cm}$ (4 in.);

- Air content: 1.8 percent;

- Unit weight: $2400 \mathrm{~kg} / \mathrm{m}^{3}\left(2,900 \mathrm{lbs} / \mathrm{ft}^{3}\right)$.

The mixed fresh concrete was carefully placed in the instrumented concrete form. PCC cylinders were also prepared for compressive strength testing.

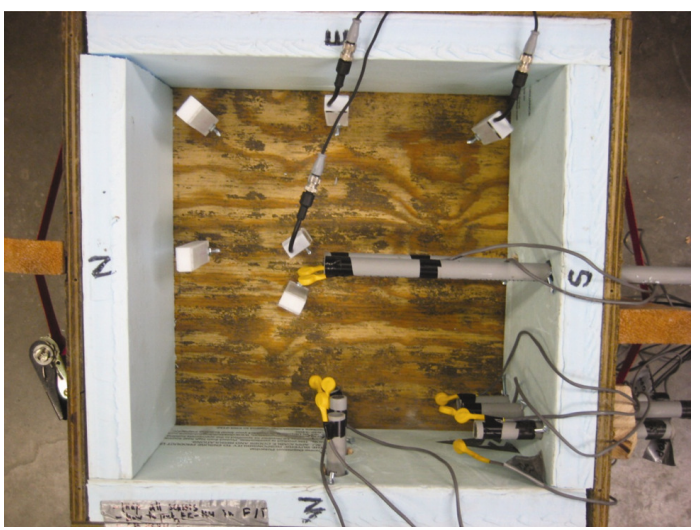

a)

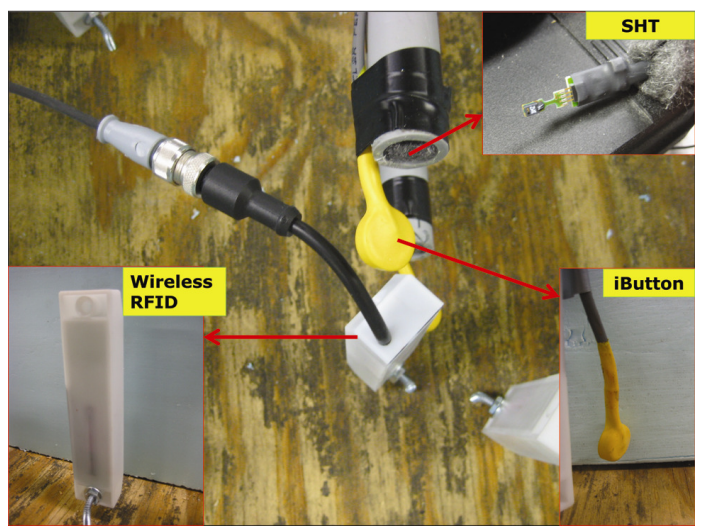

b)

Fig. 4. Instrumented concrete form: a) plan view; b) installed sensor types
The data acquisition system consisted of the data readers for sensors and a laptop computer. The data readers for wireless RFID and the digital humidity sensors include the portable Pro and the EK-H4 evaluation kit, respectively. Both readers can interface with the laptop computer through a USB port. Temperature and humidity data were acquired from the MEMS sensors in accordance with the experimental test program described in the next section.

\subsection{Test program}

The experimental test program in this study consisted of four test phases based on different test conditions. Table 2 summarizes the experimental test program designed to investigate the feasibility of MEMS sensors for continuous monitoring of concrete pavements.

Table 2. Summary of experimental test program

\begin{tabular}{|c|c|c|c|}
\hline $\begin{array}{c}\text { Test } \\
\text { Phase }\end{array}$ & Period & Location & Note \\
\hline 1 & $\begin{array}{c}10 / 07 / 2010 \\
- \\
10 / 12 / 2010\end{array}$ & $\begin{array}{l}\text { ISU PCC } \\
\text { laboratory }\end{array}$ & $\begin{array}{l}\text { - Room temperature } \\
\text { conditions } \\
- \text { Cement hydration in } \\
\text { concrete }\end{array}$ \\
\hline 2 & $\begin{array}{c}10 / 19 / 2010 \\
- \\
10 / 24 / 2010\end{array}$ & $\begin{array}{l}\text { Freezing } \\
\text { and thaw- } \\
\text { ing room }\end{array}$ & $\begin{array}{l}\text { - Five rapid freeze-thaw } \\
\text { cycles } \\
\text { - Each freeze-thaw } \\
\text { cycle lasting a day } \\
\text { with temperatures } \\
\text { ranging from } 0^{\circ} \mathrm{F} \text { to } \\
50^{\circ} \mathrm{F}\end{array}$ \\
\hline 3 & $\begin{array}{c}10 / 26 / 2010 \\
- \\
11 / 01 / 2010\end{array}$ & $\begin{array}{l}\text { Freezing } \\
\text { and thaw- } \\
\text { ing room }\end{array}$ & $\begin{array}{l}\text { - One slow freeze-thaw } \\
\text { cycle } \\
\text { - Freeze-thaw cycle } \\
\text { lasting six days with } \\
\text { temperatures ranging } \\
\text { from } 0{ }^{\circ} \mathrm{F} \text { to } 70^{\circ} \mathrm{F} \\
\end{array}$ \\
\hline 4 & $\begin{array}{c}11 / 13 / 2010 \\
- \\
04 / 23 / 2011\end{array}$ & $\begin{array}{l}\text { Driveway } \\
\text { in Ames, } \\
\text { Iowa }\end{array}$ & $\begin{array}{l}\text { - Actual Iowa road } \\
\text { conditions } \\
\text { - Air temperatures } \\
\text { ranging from } 0^{\circ} \mathrm{F} \text { to } \\
80^{\circ} \mathrm{F} \\
\end{array}$ \\
\hline
\end{tabular}

During the first test phase, the installed sensors measured the temperature variations inside the slab produced by generation of heat during cement hydration. The temperature data collected during this phase was also used to estimate the extent of hydration and PCC strength gain through the maturity concept, as will be discussed later.

During test phases 2 and 3, the instrumented slab was placed in a freezing and thawing room at the ISU PCC laboratory. The second test phase involved five rapid freezing and thawing cycles. Each cycle lasted about a day ( 24 hours) and the temperature variation of each cycle ranged from $0{ }^{\circ} \mathrm{F}$ to $50{ }^{\circ} \mathrm{F}$. The test phase 3 adopted one cycle of slow freezing and thawing condition. The duration of the one cycle was about six days and the temperature variation ranged from $0{ }^{\circ} \mathrm{F}$ to $70^{\circ} \mathrm{F}$. In the fourth experimental test phase, the MEMS sensor measurement capacity and robustness in actual field/in 
situ conditions was evaluated by burying the instrumented slab underground near a driveway in Ames, Iowa.

Figure 5 displays the pictures of the instrumented slab subjected to four different experimental test phases. The sensor measurement data were collected at the end of each test phase.

a)
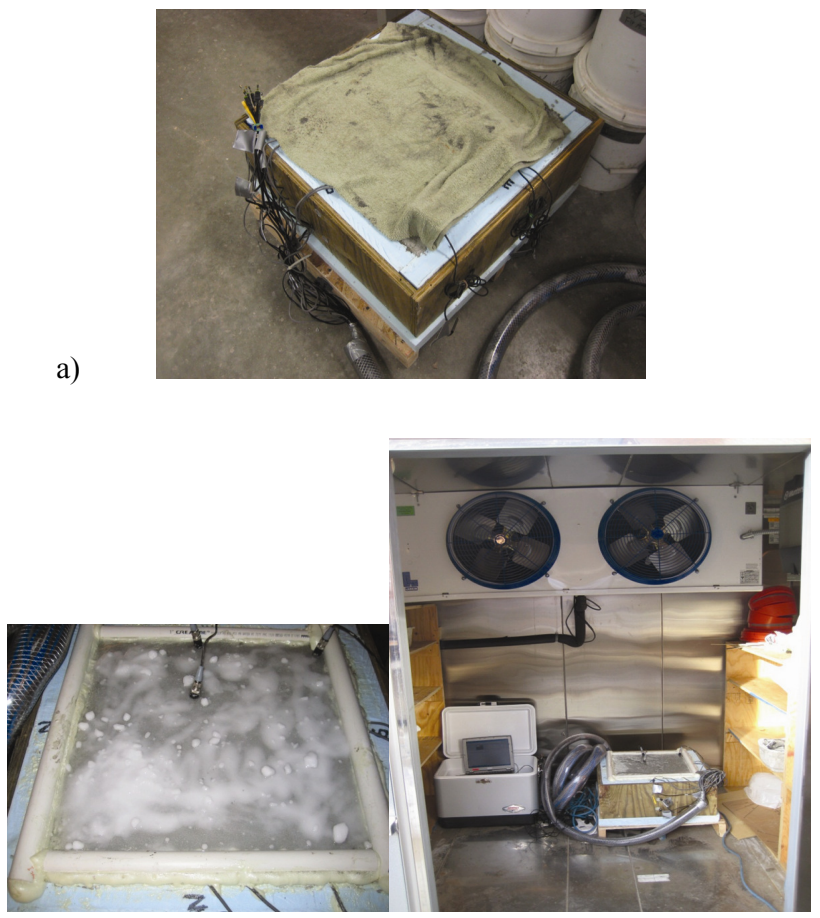

b)

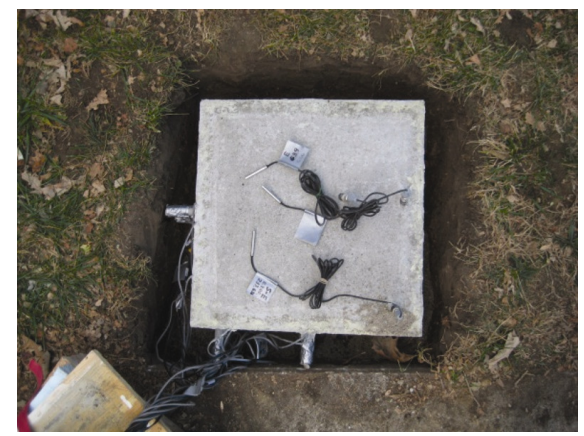

c)

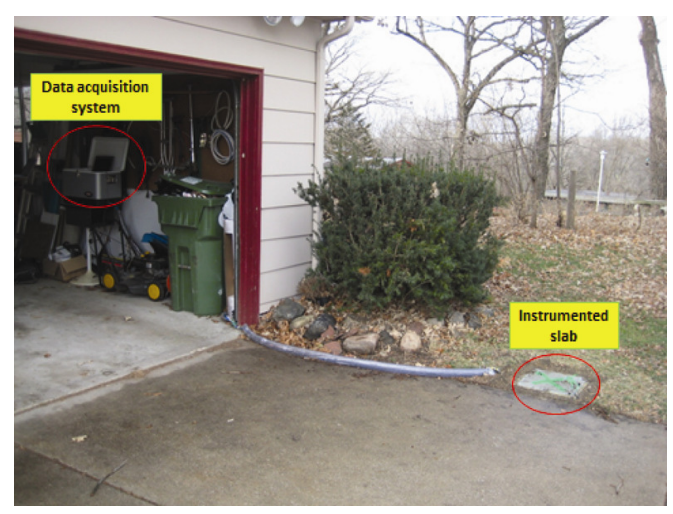

Fig. 5. Instrumented slab tested under different experimental conditions: a) phase 1 ; b) phases 2 and 3 ; and c) phase 4

\subsection{Laboratory and field test results}

The ASTM C 1074, Standard Practice for Estimating Concrete Strength by the Maturity Method, describes the procedure for estimating concrete strength using maturity concepts, based on the principle that concrete strength (and other properties) is directly related to both age and its temperature history. According to ASTM C 1074, the maturity method is "...a technique for estimating concrete strength that is based on the assumption that samples of a given concrete mixture attain equal strengths if they attain equal values of maturity index".

ASTM C 1074 provides two types of maturity functions: 1) the Nurse-Saul function, which assumes that the rate of strength development is a linear function of temperature; and 2) the Arrhenius function, which assumes that the rate of strength development follows an exponential relationship with temperature.

The more commonly used Nurse-Saul equation is expressed as follows:

$$
M=\sum_{0}^{t}\left(T-T_{0}\right) \Delta t,
$$

where: $M=$ maturity or Temperature-Time Factor (TTF) (usually in ${ }^{\circ} \mathrm{C}$-hours or ${ }^{\circ} \mathrm{C}$-days); $t=$ time interval being considered; $\Delta t=$ time interval; $T=$ average temperature of the PCC during the time interval $(\Delta \mathrm{t})$ being considered; $T_{0}=$ datum temperature - the temperature below which PCC shows no strength gain with time $\left(-10{ }^{\circ} \mathrm{C}\right.$ $\left(14^{\circ} \mathrm{F}\right)$ is most commonly used).

The curves for maturity are built using test data from either compressive strength cylinders or flexural strength beams. In this research study, compressive strengths were determined in the lab by testing PCC cylinders at different ages. Figure 6 displays the maturity curve determined from wireless RFID temperature sensor data, as well as from other sensors, along with the laboratory-measured compressive strength data.

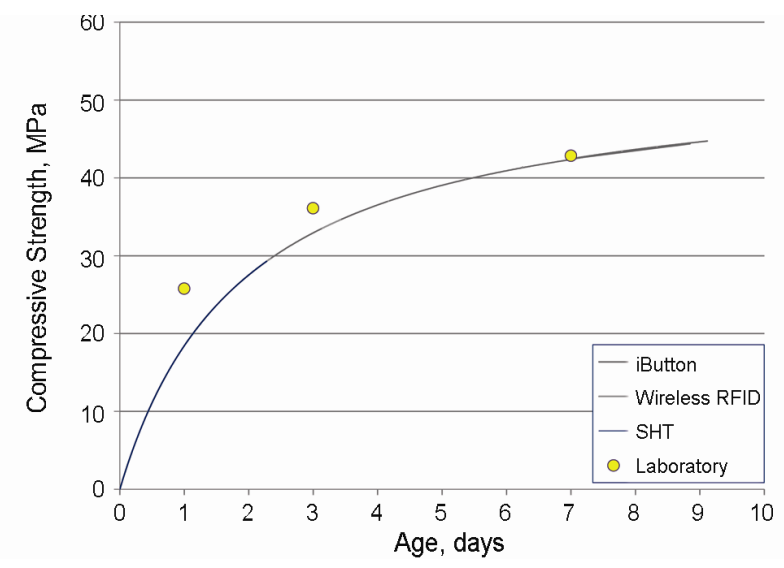

Fig. 6. Concrete maturity curve

Figure 7 captures the temperature measurements recorded by the sensors at the slab centre during test phase 1 . All installed sensors were able to capture the heat of cement hydration behaviour in concrete during the first three days after the fresh concrete was placed. However, the SHT sensors were not always functional. Comparison to 
iButtons, the wireless RFID sensors send measurement signals about five hours later. Similar findings were observed for the edge-of-slab sensors and for the corner-ofslab sensors.

Temperature measurements from iButton sensors and wireless RFID tags during test phase 2 are presented in Figure 8. Through these series of tests, the capability of wireless RFID tags to work properly in high-severity temperature conditions was demonstrated because they provided comparable temperature measurements to iButton sensors. Although the SHT sensors were placed inside the slab, they didn't function properly for some reason. Similar findings were observed for the edge-of-slab sensors and corner-of-slab sensors.

Test phase 3 adopted slow freezing and thawing conditions (while test phase 2 involved rapid freezing and
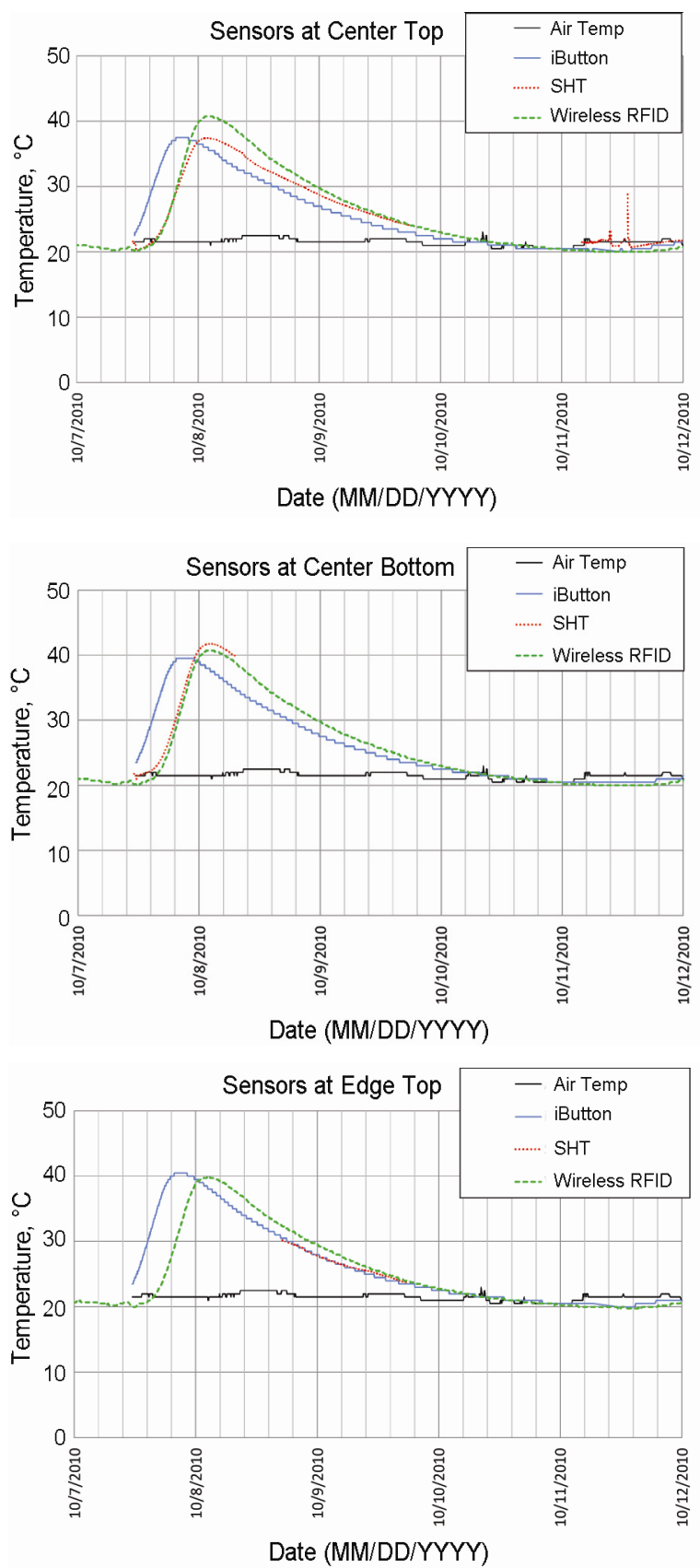

thawing conditions). Temperature measurements from all three types of sensors for test phase 3 are presented in Figure 9. The temperature measurements of wireless RFID sensors placed in the slab center are similar to those measured by the wired iButton sensors placed in the middle and bottom of the slab at each location as shown in Figure 9. Similarly, the temperature measurements of the SHT sensors at the corresponding location and depth are similar to those of the wired iButton sensors. Relative Humidity (RH) measurements from the SHT sensors are presented in Figure 10. As seen in this figure, the SHT sensors are able to measure humidity in slow freeze-thaw conditions. These results indicate that the SHT sensors can only be utilized in concrete temperature measurements under limited conditions of slow ambient temperature changes.
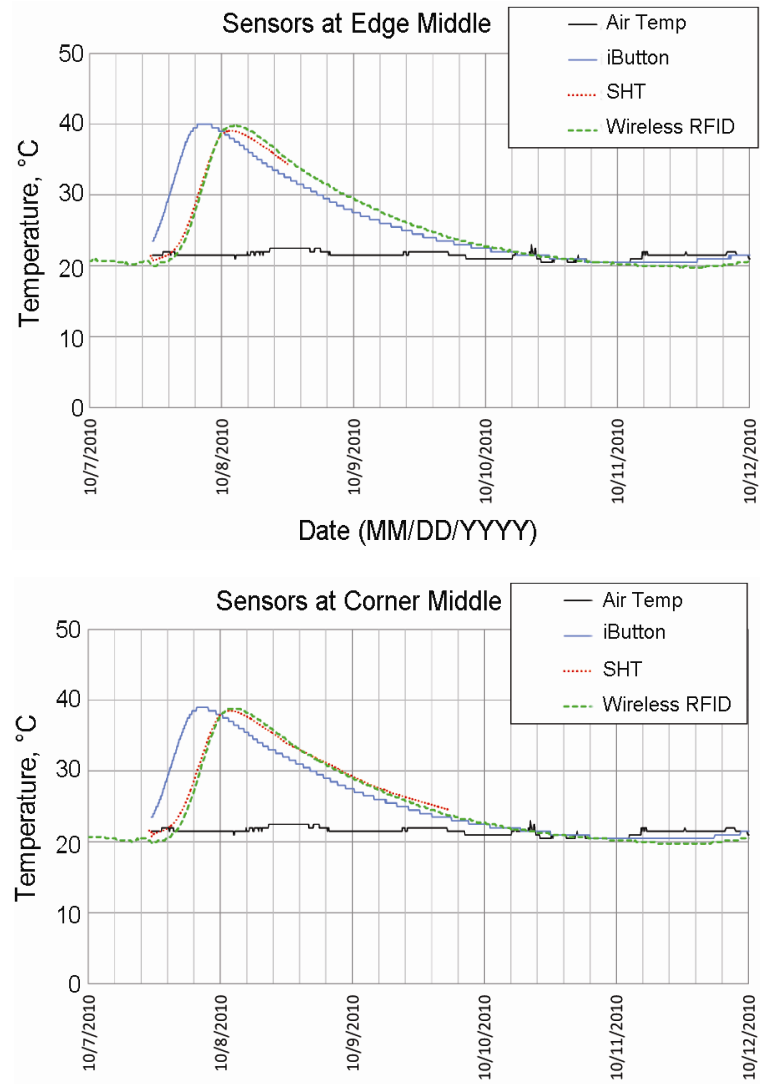

Date (MM/DD/YYYY)

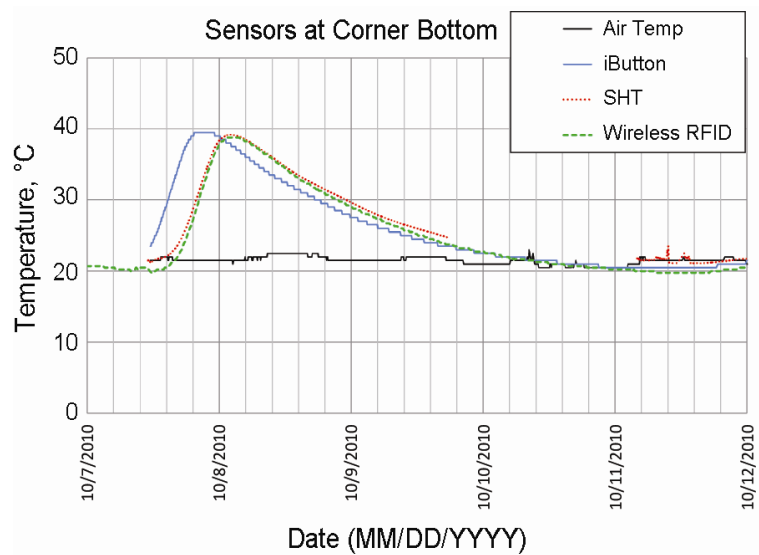

Fig. 7. Temperature measurements during test phase 1 

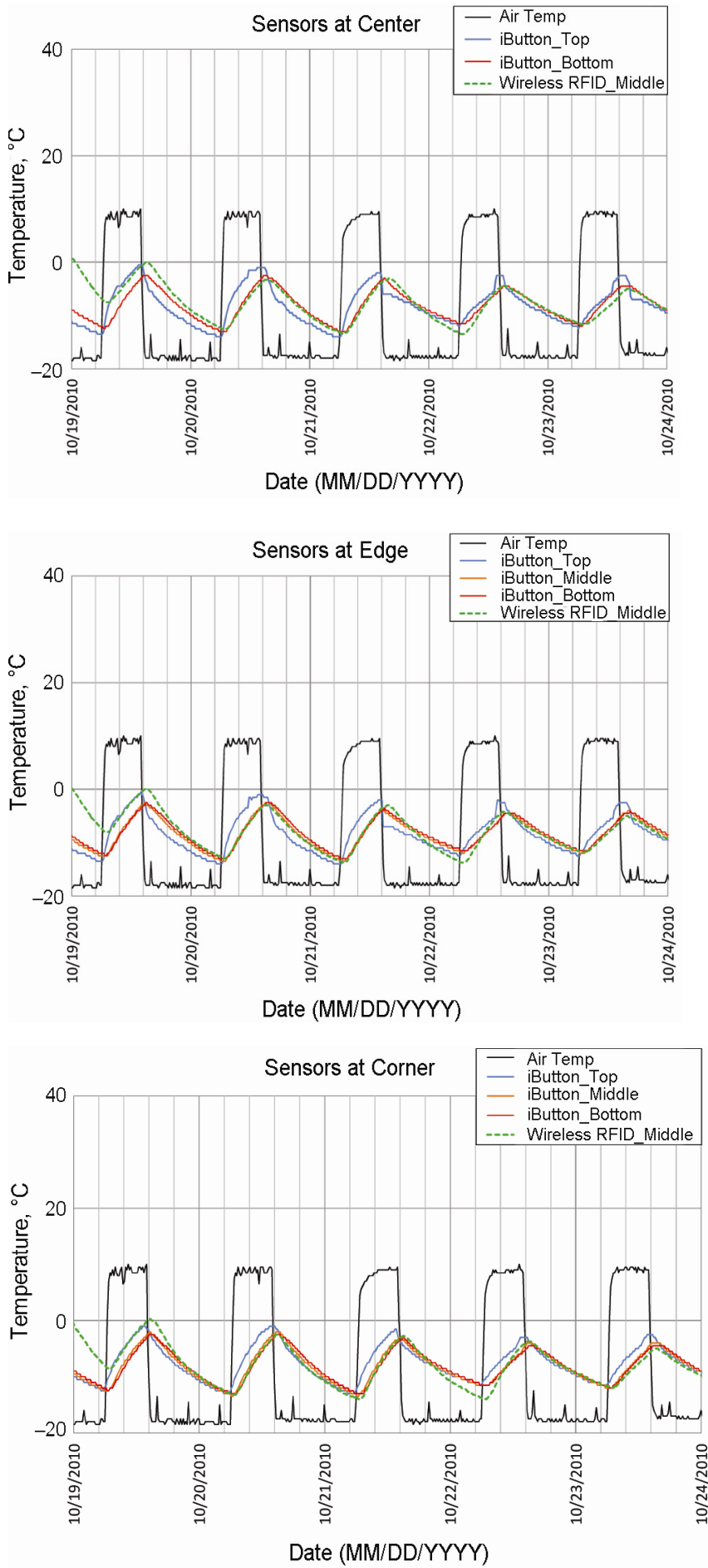

Fig. 8. Temperature measurements during test phase 2

The fourth test phase focused on evaluation of wireless RFID sensor capacity under actual road climate conditions. The instrumented slab was placed near a driveway in Ames, Iowa. Wired iButton sensors were installed on top of the PCC slab. Temperature measurements from wired iButton sensors and wireless RFID tags during test phase 4 are presented in Figure 11. The SHT sensors did not survive the harsh winter environment or became dysfunctional due to other unknown reasons. As seen in this figure, both sensors are capable of measuring in situ temperature variations inside concrete in harsh weather conditions.

\subsection{Discussion}

The body of knowledge, as well as technology related to RFID, MEMS, and nanotechnology is constantly developing. Many research studies are currently being carried out to investigate the potential application of these technologies for highway infrastructure condition monitoring.

A significant advantage of the wireless RFID sensor for temperature monitoring of concrete is that the temperature data can be wirelessly transmitted directly to the construction staff and used to alert project staff to temperature-related events in the concrete, such as freezing or elevated curing temperatures. In addition, models to forecast the future strength of the concrete can be incorporated into the system, which is very helpful for future scheduling and decision-making. Based on the continuous information available to monitor the maturity or strength of concrete in real time, decisions can be made more effectively for opening newly-constructed pavements, patches, or overlays much faster. This results in saving on construction time and reducing the traffic congestion due to lane closures.

The RFID-based concrete monitoring system could also be used to monitor strength gain in concrete bridges, etc. In addition, questions like how many number of freeze-thaw cycles a concrete pavement section has undergone, was it frozen during its early strength gain, did the concrete get too hot, etc. could be answered, which is also useful in characterizing the early-age curling behavior of the PCC (DeFinis 2004).

Another major benefit is that the effects of cold or hot weather on mix designs containing certain materials could be studied using the RFID-based concrete monitoring system. For instance, by placing concrete containing fly ash/ground granulated blast furnace slag (GGBFS) (which slows down strength gain in cold weather) and monitoring the strength gain, a temperature-dependent specification (with the amount of fly ash/GGBFS) could be specified, rather than a date-dependent specification (DeFinis 2004). Research is underway for developing RFID-based humidity tracking tags, which will have even greater potential in concrete infrastructure monitoring.

MEMS applications vary immensely and the multidisciplinary nature of these sensor systems allow engineers with different backgrounds to collaborate on the same research projects. A diverse research team will help in developing more useful applications for MEMS while the challenges are overcome. Many challenges with MEMS systems remain primarily in the sensor systems that transfer, relay, and process data (Saafi, Romine 2005). The top four challenges to overcome are packaging technology, energy supply, internal and external methods of communication within the micro-system, and signal possessing and control (Ko 1996).

One new development is showing promise in the area of energy supply. Although a number of potential selfpowering energy sources have been identified (e.g. solar power, thermal gradient, piezoelectric, vibrational), only a few are capable of providing the continuous power required to operate a single sensor (Lajnef et al. 2008). There are research projects currently exploring the possibilities of 

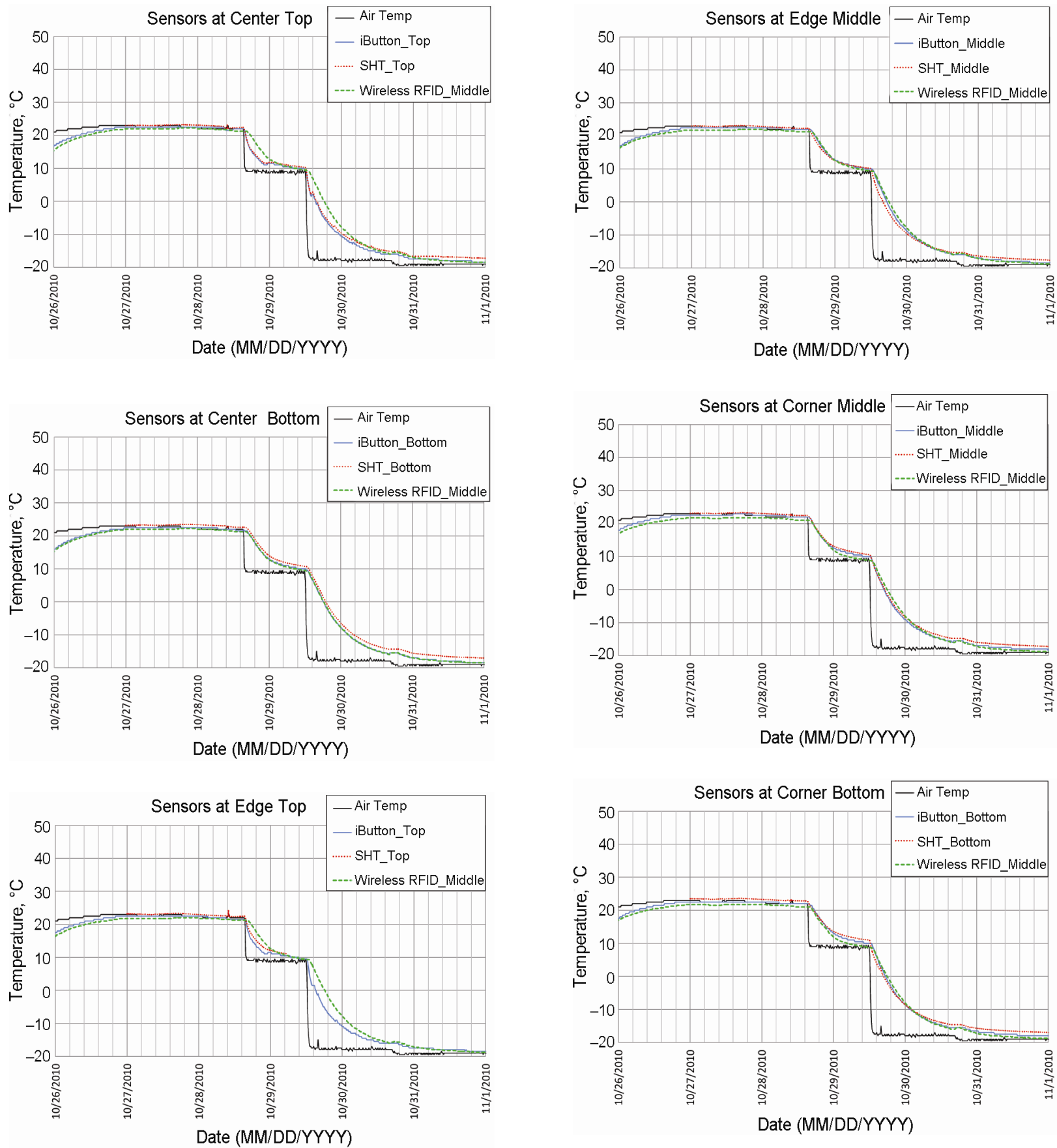

Fig. 9. Temperature measurements during test phase 3

using nuclear energy in the form of a micro battery. These batteries would be able to last for long periods of time, which would minimize the need to replace batteries for active sensors. The micro size of the battery would also allow a significant size reduction for active sensors. This technology is still in the beginning phases and it will be a few years until any prototypes are available. One challenge researchers already face is keeping the cost of these nuclear batteries affordable. The cost increases with the number of radioisotopes used (Wagner 2007).

In today's societies, multiple, but individual, operational infrastructures, such as transportation and power grids, exist together and are connected via physical, cyber, and logical interdependencies to function as a tightly-coupled, socio-technical system of systems with complicated behaviour (Gopalakrishnan, Peeta 2010). Continuous, reliable operation and resilience of such critical, interdependent infrastructures is crucial for maintaining homeland security, economic prosperity, and the quality of people's lives. In addition, there is a pressing need to optimize resources with the given social, economic, and environmental considerations. In consideration of this emerging scenario, it is inevitable that the future sustainable and smart highway systems will integrate components such as renewable energy-based transportation, energy-efficient pavement technologies, contextsensitive elements, wireless MEMS and RFID systems, etc. 

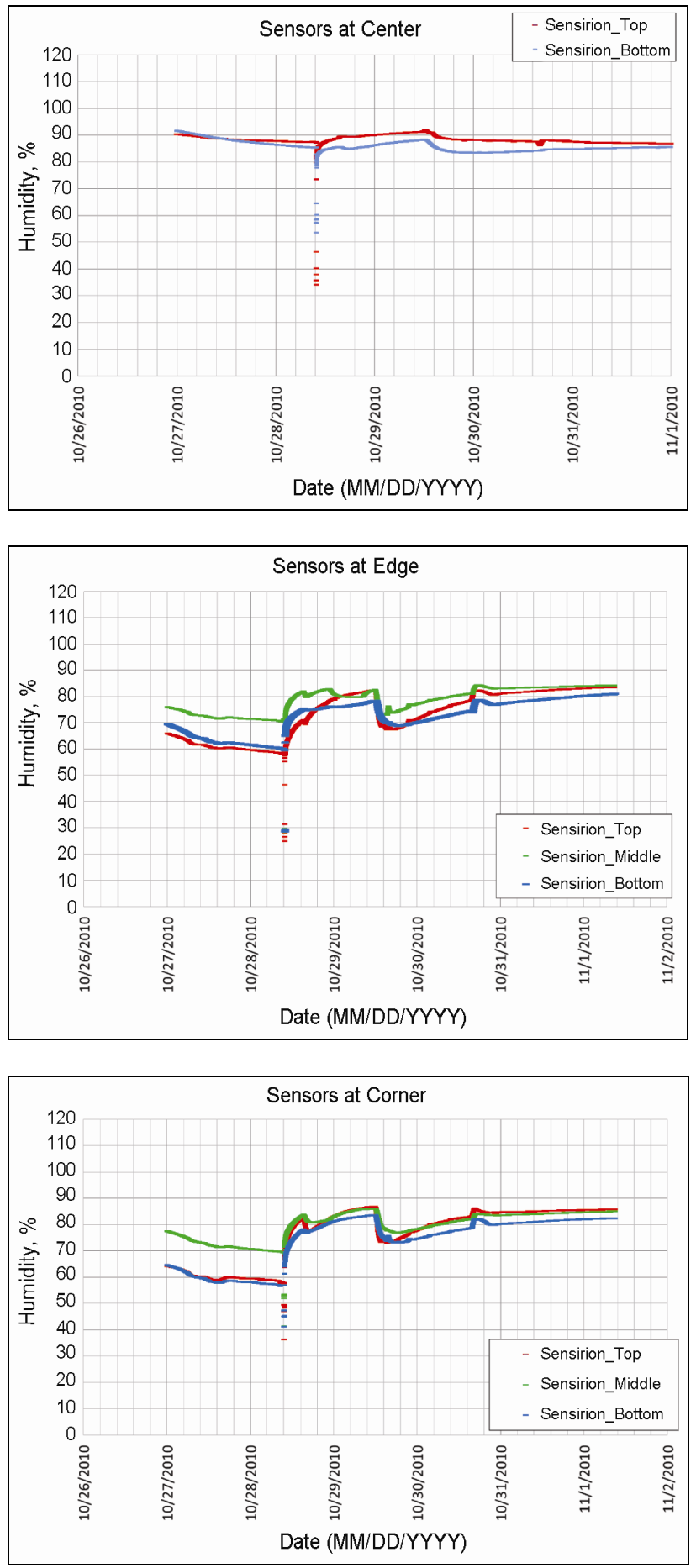

Fig. 10. Humidity measurements during test phase 3

\section{Summary and conclusions}

It has been reported that MEMS are on course to revolutionize transportation infrastructure health monitoring and infrastructure management. MEMS sensors have become a reality in today's world, although there are still many developments needed in order to implement this technology.

There are different challenges for each different type of system. The passive systems face challenges with wireless interrogation. These challenges include power transfer, data storage, and processing (Norris et al. 2006). One of the issues that both active and passive systems
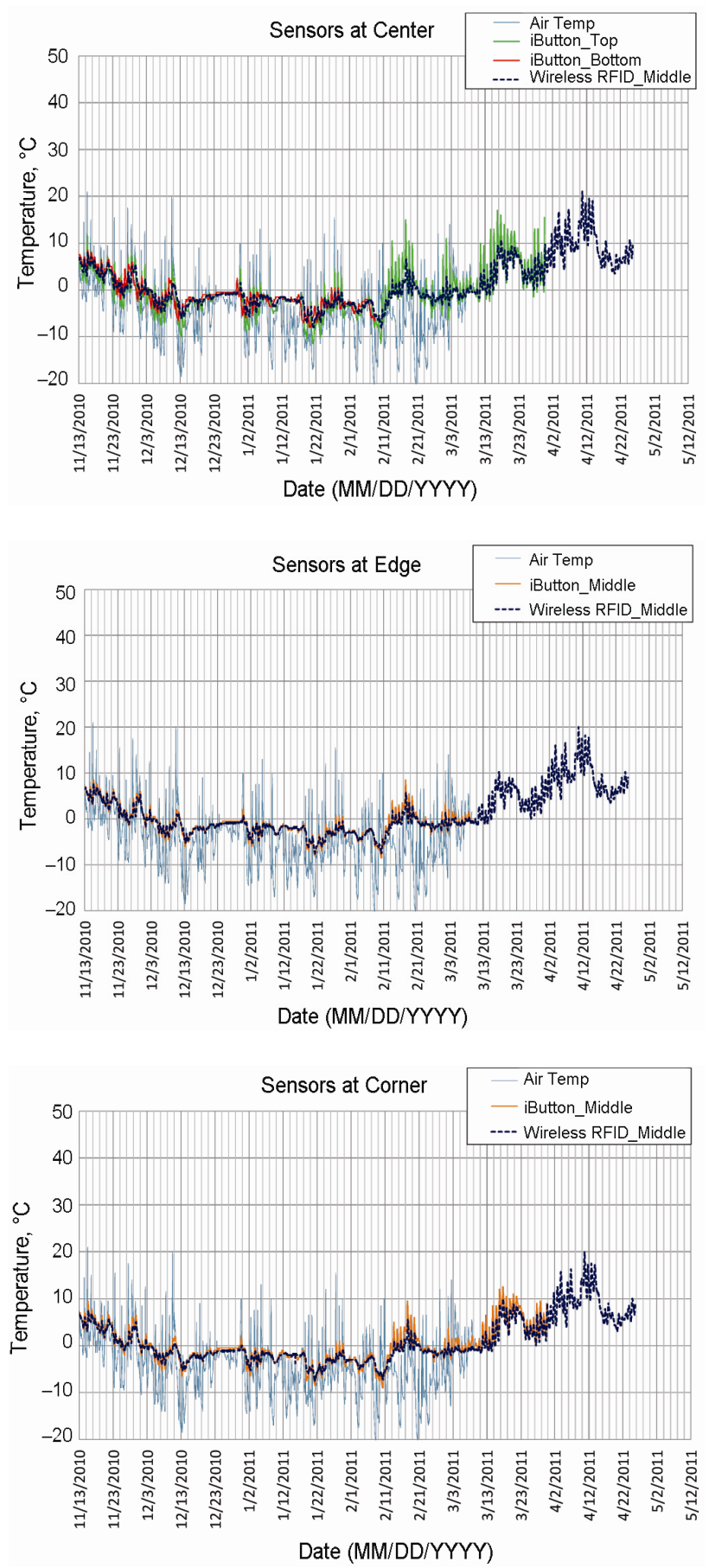

Fig. 11. Temperature measurements during test phase 4 showing freezing cycles

face is durable packaging that still allows the system to be cost effective. Packaging remains to be applicationspecific and the cost can vary between 75 and 95 percent of the overall cost (Attoh-Okine 2003).

The small size and ability for bulk production works as an advantage for MEMS. The small size means less material is needed for packaging and bulk production allows the sensors to be manufactured at a low unit cost. For example, the WESP system has been projected to cost as little as $\$ 10$ per unit (Cain et al. 2001). Reliable MEMS sensor systems at low costs would have the ability to change day-to-day SHM practices. 
As these systems become more available, we will begin to see an increase in smart structures and roads that could help engineers make better informed maintenance decisions and ensure the safety of the traveling public. Despite the many challenges, there are some sensor systems that are commercially available. To overcome many of these challenges, research to improve the MEMS sensors will continue.

A number of other challenges were identified by Steyn (2008) and Wang, Li (2008) with respect to the wide-scale implementation of MEMS/nanotechnology in highway infrastructure applications:

- Extensively-funded research programs for development and full-scale evaluation of the MEMS products are required since they are generally developed for custom-specific applications;

- Leaching of nanomaterials and byproducts of MEMS sensor construction material interactions into groundwater, release of toxic materials into airways through the generation of dust, and exposure to potentially harmful materials during construction and maintenance operations are some potential environmental impacts of using nanomaterials/MEMS that have not yet been researched;

- The impacts of embedding the sensor on the performance of a structure and vice versa need to be assessed apart from the survivability of the sensor itself for long-term stable operation.

\section{References}

Advanced Design Consulting (ADC). 2008. MEMS Concrete Monitoring System [online], [cited 11 July 2008]. Available from Internet: http://www.adc9001.com/index.php? $\mathrm{src}=$ memsconcrete $\&$ PHPSESSID $=\mathrm{d} 32 \mathrm{bcf} 6 \mathrm{~d} 1821582 \mathrm{ef0a}$ $07 \mathrm{c} 7 \mathrm{~b} 0 \mathrm{acbc} 983$

ASTM C 1074. 1998. Standard practice for estimating concrete strength by the maturity method, in Annual book of ASTM standards. ASTM International, West Conshohocken, PA.

Attoh-Okine, N. O. 2003. Transportation Research Circular No. E-C056: The future of MEMS in transportation infrastructure systems. Transportation Research Board, National Research Council, Washington, DC.

Cain, R. P.; Carkhuff, B. G.; Srinivasan, R.; Grossman, K. R.; Weiskopf, F. 2001. Packaging for a sensor platform embedded in concrete, in MRS Proceedings 682: 3.9. http://dx.doi.org/10.1557/PROC-682-N3.9

Darrin, M. A. G.; Carkhuff, B. G.; Mehoke, T. S. 2004. Future trends in miniaturization for wireless applications, John Hopkins APL Technical Digest 25(4): 343-347.

DeFinis, A. J. 2004. Concrete maturity testing in Michigan [online], [cited February 2004]. Available from Internet: http://www.wakeinc.com/PDF/mich2004.pdf

Durfee, A.; Goodrum, P. 2002. RFID, MEMS, and their application in the field of construction: White Paper. University of Kentucky, Lexington, Kentucky.

Gaura, E.; Newman, R. 2006. Smart MEMS and sensor systems. London: Imperial College Press.

Gopalakrishnan, K.; Peeta, S. 2010. Sustainable and resilient critical infrastructure systems: simulation, modeling, and intelligent engineering. Springer, Inc. 300 p.
Huang, C.; Lajnef, N.; Chakrabartty, S. 2010. Self-calibration and characterization of self-powered floating gate usage monitors with single electron per second operational limit, IEEE Transactions of Circuits and Systems I 57(3): 556567. http://dx.doi.org/10.1109/TCSI.2009.2024976

Iaquinta, J. 2008. Client Project Report CPR 484: Use of microelectro-mechanical systems and wireless sensor networks on road infrastructures. Transport Research Foundation (TRF), Transport Research Laboratory (TRL), United Kingdom.

Ko, W. 1996. The future of sensor and actuator systems, Sensors and Actuators A: Physical 56(1-2): 193-197. http://dx.doi.org/10.1016/0924-4247(96)01288-5

Korvink, J.; Paul, O. 2006. MEMS: a practical guide to design, analysis, and applications. Norwich: W. Andrew Publishing.

Kosmatka, S.; Kerkhoff, B.; Panarese, W. C. 2002. Design and control of concrete mixes. $14^{\text {th }}$ ed. Portland Cement Association, Skokie, IL.

Kuennen, T. 2004. Road science: small science will bring big changes to roads, Better Roads Magazine, July [online], [cited 19 October 2010]. Available from Internet: http://www.betterroads.com/road-science/

Lajnef, N.; Chakrabartty, S.; Elvin, N. 2008. A piezo powered floating-gate sensor array for long-term fatigue monitoring in biomechanical implants, IEEE Transactions on Biomedical Circuits and Systems 2(3): 164-72.

http://dx.doi.org/10.1109/TBCAS.2008.2001473

Lajnef, N.; Rhimi, M.; Chatti, K.; Mhamdi, M.; Faridazar, F. 2011. Toward an integrated smart sensing system and data interpretation techniques for pavement fatigue monitoring, Computer-Aided Civil and Infrastructure Engineering 26(7): 513-523. http://dx.doi.org/10.1111/j.1467-8667.2010.00712.x

Liu, R.; Zhang, Z.; Zhong, R.; Chen, X.; Li, J. 2007. Report No. FHWA/TX-07/0-5239-1: Nanotechnology synthesis study: research report. University of Houston, Houston, TX.

Maluf, N. 2000. An introduction to microelectromechanical systems engineering. Massachusetts, Boston: Artech House.

Mensah, S. 2003. Civil infrastructure monitoring using microelectromechanical systems (MEMS): a case study for concrete microcracking, in Proceedings of the 2003 TRB Annual Meeting (CD-ROM), Jan. 12-16, Washington, DC, USA.

Norris, A.; Saafi, M.; Romine, P. 2006. Temperature and moisture monitoring in concrete structures using embedded nanotechnology/microelectromechanical systems (MEMS) sensors, Construction and Building Materials 22(2): 111120. http://dx.doi.org/10.1016/j.conbuildmat.2006.05.047

Obadat, M.; Lee, H.; Bhatti, M. A.; Mclean, B. 2003. Full-scale field evaluation of microelectromechanical system-based biaxial strain transducer and its application in fatigue analysis, Journal of Aerospace Engineering 16(3): 100107. http://dx.doi.org/10.1061/(ASCE)0893-1321(2003) $16: 3(100)$

Ong, J. B.; You, Z.; Mills-Beale, J.; Tan, E. L.; Pereles, B. D.; Ong, K. G. 2008. A wireless passive embedded sensor for real-time monitoring of water content in civil engineering materials, IEEE Sensors Journal 8(12): 2053-2058. http://dx.doi.org/10.1109/JSEN.2008.2007681

Ozevin, D.; Greeve, D. W.; Oppenheim, I. J.; Pessiki, S. P. 2006. Resonant capacitive MEMS acoustic emission transducers, Smart Materials and Structures 15(6): 18631871. http://dx.doi.org/10.1088/0964-1726/15/6/041 
Phares, B. M.; Wipf, T. J.; Greimann, L. F.; Lee, Y. 2005. Report No. 0092-04-14: Health monitoring of bridge structures and components using smart-structure technologyVolume 1. Center for Transportation Research and Education (CTRE), Iowa State University, Ames, IA.

Pei, J. S.; Ivey, R. A.; Lin, H. J.; Landrum, A. R.; Sandburg, C. J.; King, T.; Ferzli, N. A.; Zaman, M. M.; Refai, H. H. 2007. A "Smart Dust"-based road condition monitoring system: performance of a small wireless sensor network using surge time synchronization, in Proceedings of the IMAC$X X V$ Conference, Society for Experimental Mechanics (SEM), Feb. 12-22, Orlando, Florida.

Pei, J. S.; Ivey, R. A.; Lin, H.; Landrum, A. R.; Sandburg, C. J.; Ferzli, N. A.; King, T.; Zaman, M. M.; Refai, H. H.; Mai, E. C. 2009. An experimental investigation of applying Mica2 motes in pavement condition monitoring, Journal of Intelligent Material Systems and Structures 2(1): 63-85. http://dx.doi.org/10.1177/1045389X08088785

Saafi, M.; Romine, P. 2005. Preliminary evaluation of MEMS devices for early age concrete property monitoring, Cement and Concrete Research 35(11): 2158-2164. http://dx.doi.org/10.1016/j.cemconres.2005.03.012

Saafi, M.; Kaabi, L. 2009. Low-cost wireless nanotube composite sensor for damage detection of civil infrastructure, Sensors and Transducers 110(11): 96-104.

Saafi, M.; Kaabi, L.; McCoy, M.; Romine, P. 2010. Wireless and embedded nanotechnology-based systems for structural integrity monitoring of civil structures: a feasibility study, International Journal of Materials and Structural Integrity 4(1): 1-24.

http://dx.doi.org/10.1504/IJMSI.2010.032494

Sandia National Labs. 2007. Sensor may monitor aircraft for defects continuously. News Releases [online], [cited 18
July 2007]. Available from Internet: https://share.sandia. gov/news/resources/releases/2007/aircraft.html

Srinivasan, R.; Carkhuff, B. G.; Phillips, T. E.; Saffarian, H.; Davis, G. D.; Raghu, S. 2005. Miniature wireless full spectrum EIS corrosion sensor, in The Tri-Services conference on Corrosion, Nov. 14-18, Orlando, FL.

Steyn, W. J. 2008. Potential applications of nanotechnology in pavement engineering, Journal of Transportation Engineering 135(10): 764-772. http://dx.doi.org/10.1061/ (ASCE)0733-947X(2009)135:10(764)

Tanner, P. 2001. Present and future capabilities of MEMS and smart sensors at Griffith University, in the $19^{\text {th }}$ Annual Microelectronic Engineering Research Conference, May 9-10, Rochester Institute of Technology, Rochester, NY.

Technology Review. 2003. Smart Pebbles [online], [cited 17 July 2003]. Available from Internet: www.technologyreview.com.

Wagner, S. 2007. Battery technology: powers to be. London: Centaur Publishing, Ltd.

Wang, K. C. P.; Li, Q. 2008. Final report for project MBTC2056: Applicability of Microelectronic and Mechanical Systems (MEMS) for transportation infrastructure management. Department of Civil Engineering, University of Arkansas, Fayetteville, AR.

Watters, D. G.; Palitha, J.; Bahr, A. J.; Huestis, D. L.; Priyantha, N.; Meline, R.; Reis, R.; Parks, D. 2003. Smart Pebble: wireless sensors for structural health monitoring of bridge decks, in Proceedings of the SPIE, Smart Structures and Materials 2003: Smart Systems and Nondestructive Evaluation for Civil Infrastructures, 2 March, 2003, 5057: 2028. http://dx.doi.org/10.1117/12.482397

Halil CEYLAN. Associate Professor in the Department of Civil Construction, and Environmental Engineering at Iowa State University, Member of the American Society of Civil Engineers (ASCE) as well as an Editorial Board Member of the Baltic Journal of Road and Bridge Engineering. Received his PhD at the University of Illinois at Urbana-Champaign, USA. His research interests include the nondestructive testing and evaluation, mechanistic-based pavement analysis, design and performance prediction, and sustainable infrastructure/engineering materials.

Kasthurirangan GOPALAKRISHNAN. Senior Research Faculty in the Department of Civil Construction, and Environmental Engineering at Iowa State University, Member of the American Society of Civil Engineers (ASCE) as well as an Editor of the Transport and International Journal for Traffic and Transport Engineering. He received the Dwight D. Eisenhower Transportation Fellowship award in 1999 and he completed his PhD in 2004 at the University of Illinois at Urbana-Champaign, USA. His research interests include the use of bio-inspired computing paradigms in civil engineering informatics, sustainable and green technologies, simulation, imaging, and mechanics of transportation infrastructure systems.

Sunghwan KIM. Research Assistant Professor in the Department of Civil Construction, and Environmental Engineering at Iowa State University, Member of the American Society of Civil Engineers (ASCE) as well as the Association of Asphalt Paving Technologists (AAPT). Received his PhD in 2006 at Iowa State University, USA. His research interests include the renewable transportation infrastructure materials and recycling construction technique, the mechanistic-based pavement analysis and design, and the nondestructive testing and evaluation (NDE) of transportation infrastructure systems. He is a registered professional engineer (P.E.) in the state of Michigan, USA.

Peter C. TAYLOR. Associate Director of the National Center for Concrete Pavement Technology (CP Tech Center) at Iowa State University, active Member of the active member of the Transportation Research Board (TRB), American Society for Testing and Materials (ASTM) and American Concrete Institute (ACI). Received his PhD in civil engineering from the University of Cape Town, South Africa in 1995. His prime research interests include concrete durability, including the development of test methods for assessing the potential durability of concrete mixtures. He is a registered professional engineer (P.E.) in the state of Illinois, USA.

Maxim PROKUDIN. Geotechnical Engineer at SPL Consultants Limited (Toronto, ON), Member of the Society of Mining Metallurgy and Exploration and Association of Environmental and Engineering Geologists. Received his MS in Civil Engineering from Iowa State University in 2009. Professional interests include geotechnical, materials and mining engineering.

Ashley F. BUSS. PhD Candidate in the Department of Civil, Construction and Environmental Engineering at Iowa State University. Received her MS in Civil Engineering from Iowa State University in 2010. Her research interests include evaluation of warm mix asphalt technologies, non-destructive testing and evaluation, and asphalt performance tests. 